comprises the remainder of the country under review, extending northwards to include a strip of Southern Rhodesia and the southern part of Portuguese East Africa, There are also chapters on the physical features and climate, on methods of survey, with instructions to collectors and observers, and a bibliography. Dr. Marloth writes on the use of the common names of plants, which, though sometimes not trustworthy, may be very useful if accepted with care and discretion.

The Report of the Canadian Arctic Expedition I9r $3-18$ (voi. v., Botany, part B) by Theo. Holm ("Contributions to the Morphology, Synonymy, and Geographical Distribution of Arctic Plants ") contains some interesting notes on the methods of growth and reproduction, manner of hibernation and other characteristics, of many of the species collected by the expedition. Certain biological types are absent from the polar regions; there are no climbers, no saprophytes, and no true parasites. Pedicularis alone represents the partial parasites. The great majority of the herbs are perennial. The chapter on geographical distribution contains a table showing the general distribution of the species collected, which indicates that the vegetation of the north coast of America is composed of types from various parts of the northern hemisphere of both worlds, and bears out the view that the present arctic flora consists to a great extent of remnants of the alpine floras of the tertiary period. These alpine floras were principally those of the European Alps, Altai and Baikal, the Rocky Mountains, and perhaps also Caucasus and Scandinavia.

Memoir 126, issued by the Canadian Department of Mines ("A Botanical Exploration of the North Shore of the Gulf of St. Lawrence," by Harold
St. John), includes an annotated list of all the flowering plants and ferns recorded from this area, in all 622 species, and some discussion of the soil-relations of the various ecological plant groups. A comparison of the habitats of IO3 species along the north shore of the gulf and in other regions, especially Europe, indicates an agreement the more surprising considering that the data have been gathered by many botanists at widely separated places and times. Mr. St. John also gives an account of botanical exploration in the same area previous to his own visit in I9I5.

"A Flora of the Shetlands," by Dr. G. C. Druce, forms a supplement to the recently issued report of the Botanical Society and Exchange Club for r92I. The total land surface of the islands, which number more than a hundred, is rather more than that of the Faroes, but the hills are lower and lack the marked alpine element found in the flora of the Faroes. The population of the islands since the glacial period has been explained alternatively by the existence of a land-bridge and immigration by means of birds, ocean-currents, and wind. The latter view would seem the more probable. There are practically no endemic species, and many species found in the islands are extremely local. The flowering plants and ferns number about 500 species, 59 of which have probably been introduced by man. Dr. Druce remarks on the size and brilliancy of some of the flowers, and suggests the feeble intensity of sunlight as a cause; clouds are absent from the sky only on a few days in the year, and mists are very frequent. There are few Lepidoptera; many plants are selfpollinated, and others never ripen seed. The flora approximates most closely to that of the Faroes, and is distinctly poorer than that of the Orkneys.

\title{
The Gas Industry and Coal Conservation.
}

THE annual coal output of Great Britain is about 300 million tons, of which approximately 20 million tons are carbonised annually in gasworks for the production of towns' gas. The reserves of British coal within 4000 feet of the surface were estimated in I9I5 at 197,000 million tons. In something like 600 years the coal measures of this country will be probably exhausted, and what then? The world's scramble for oil to-day indicates that a coal age will certainly not be succeeded by an oil age. Possibly we shall have learnt to tap atomic sources of energy, or perhaps the earth's internal heat may be available to us, after the manner suggested by Sir Charles Parsons.

There are those who hold that how posterity will provide itself with supplies of energy is posterity's own concern and need cause us no uneasiness; the gas industry takes a wider view. Its processes are continually being examined with a view to effecting greater conservation of coal. In a Report to the Institution of Gas Engineers in I9I.9, by Sir Dugald Clerk, Profs. Cobb and Smithells, it is shown that the thermal efficiency of the process of carbonisation of coal achieved to-day in the United Kingdom is from 70 to 80 per cent., and that debiting gas with the whole of the thermal losses of the process and allowing for transmission and other losses, at least 45 per cent. of the heat of the coal carbonised is delivered to the consumer as inflammable gas. This is a high figure, but it can be considerably improved upon if the heat content of the coke produced, amounting to more than ro cwt. per ton of coal carbonised, is made available to the consumer by the conversion of the coke into gas. The Gas Regulation Act, I920, had this point among others in view when it conferred upon individual gas undertakings freedom to declare the calorific value of the gas each would supply. As there appears to be considerable confusion of thought on this matter, perhaps it were as well if we explained briefly the nature of the component mixtures constituting towns' gas.

"We see all sights from Pole to Pole, And glance arid nod and bustle by,

And never once possess our soul, Before we die."

Blue water gas is produced from coke by passing air and steam alternately over an incandescent bed of this fuel. Its calorific value is about 300 B.Th.U. per cubic foot, and its composition is approximately represented by $\mathrm{CO}_{2}, 4.5$ per cent. ; $\mathrm{CO}, 43$ per cent. ; $\mathrm{H}_{2}, 4^{8}$ per cent. ; methane, 0.5 per cent., and nitrogen, 4 per cent. Sometimes this gas is mixed direct with coal gas in a towns' gas supply, a customary proportion being 80 per cent. of coal gas and 20 per cent. of water gas, the percentage of carbon monoxide in the resulting mixture being approximately $\mathrm{I} 4$ per cent. and the resulting calorific value about 500 B.Th.U. per cubic foot. More commonly, however, carburetted water gas, produced by enriching blue water gas with gaseous hydrocarbons derived by " cracking " various oils at high temperatures, is used for this purpose. The carbon monoxide content of carburetted water gas is on the average about 27 per cent., and, when admixed to the extent of about 20 per cent. with straight coal gas, a mixture containing approximately II per cent of carbon monoxide results. Straight coal gas produced by the high temperature distillation of coal has a calorific value of about 560 B.Th.U. per cubic foot and contains about 7 per cent. of carbon monoxide.

$$
\text { NO. 2806, VOL. I I } 2]
$$


The thermal and chemical efficiencies of manufacture of different grades of gas by various processes have been the subject of three reports by a Joint Committee of the University of Leeds and the Institution of Gas Engineers. The first Report dealt with the process of steaming the charge in continuous vertical retorts, and the results showed that the thermal efficiency of gas production increased from 54.5 per cent. without steam to a maximum of $62 \cdot \mathrm{I}$ per cent. with moderate steaming, and at the same time increased yields of tar and ammonia were obtained. These results were later confirmed by work carried out about the same time by the Fuel Research Board. The second Report showed that the efficiency of production of blue water gas as ordinarily practised in a plant without waste heat boilers, taking into account the steam required for the operation of the plant, averaged 46 per cent. In the third Report on the subject (contained in the Committee's Seventh Report, a copy of which has just been received, presented to the Institution of Gas Engineers in June I922), the Committee shows that the percentage thermal efficiency of production of carburetted water gas of calorific value about 485 B.Th.U. per cubic foot, taking into account all steam required, was increased from 59.5 per cent to 68 per cent., by the use of waste heat boilers employed for steam raising by means of waste heat in the flue gases. The efficiency of production of blue water gas was 53 per cent. and of the production of gas from oil for carburetting 90 per cent. The percentage thermal efficiency of the waste heat boilers averaged only about 46 per cent.

The problem foremost in the mind of the gas industry to-day is the production and distribution of the Therm at the cheapest price. The maximum conservation of coal within the industry will be achieved when that problem has been settled. While the Fuel Research Board could not, from the nature of the problem, specify any one grade of towns' gas as being under all conditions most suitable for production and distribution, its recommendations, embodied in the Gas Regulation Act, I920, do, for the first time in the history of the industry, enable the relative efficiencies of gas production by various processes and in different parts of the kingdom to be compared on a scientific basis. The work of the Committee to which reference is here made is evidence of the quickened interest on the part of the gas industry in these matters and an earnest of higher efficiencies yet to be realised, and a cheaper Therm still to be distributed.

\section{Optical Works of Messrs. Adam Hilger, Ltd.}

THE show-rooms of Messrs. Adam Hilger, Ltd., 75A Camden Road, London, N.W.I, contain a very interesting exhibition of optical instruments, to the inspection of which visitors are cordially invited. A short account of some of the devices and operations seen during a recent visit to the works may be of interest to readers of NATURE.

In a room devoted to the grinding and polishing of lenses and mirrors, a recently silvered mirror was being coated with a thin varnish to preserve the surface of the film which was not in contact with the glass, and was to be used to reflect light in an optical instrument in the same way that a silvered mirror is used in an astronomical telescope. The mirror was circular and about 4 inches in diameter, cathodically silvered. It was mounted by soft wax on a wooden mandril which revolved on a vertical shaft at some thousand revolutions per minute with its silvered surface uppermost. Dust was brushed from the surface by means of a fine camel's hair brush, and then a weak solution of celluloid in amyl acetate was poured upon it and left to dry, while the mirror was rapidly revolving. This left a thin film of celluloid on the mirror, which preserves its brightness. Films which are thick compared with a wave-length of light protect the silvered surface almost indefinitely, but these do not allow of the highest definition. On the other hand, films which are thin compared with a wavelength of light do not preserve the silver so well, but do not, however, in any way adversely affect the optical performance of the mirror. Films of intermediate thickness would tend to produce colours on the principle of Newton's rings.

Several prisms of rock salt were seen in process of manufacture; these cannot be ground with water as in the case of glass, owing to its dissolving action on the substance, so paraffin is used instead, and the accuracy of the rough grinding is tested by steel sets of $60^{\circ}$ angle. All finished optical surfaces are, of course, tested by interference methods, the source of light being the mercury vapour arc. A Lummer plate was being tested by this means. Newton's rings were used, and they were plainly visible in spite of the thickness of the plate.
In another room the thickness of a piece of plain parallel quartz some $1 \frac{1}{4}$ in. $\times 1 \frac{1}{4}$ in. $\times \frac{1}{8}$ in. was being measured on a Michelson interferometer. The halfcoating of silver had been removed from one of the mirrors of the instrument, and the specimen was then " contacted on " to this mirror so as to cover one half of it. The whole was then half silvered, and the distance between the two surfaces was measured in air. What appeared to be a slight scratch in the centre of the specimen was in reality a slit in the glass, of width only I6 wave-lengths of light ( $\lambda_{546} \mathrm{I}$ ). This slit was made in the manner illustrated in the accompanying diagram (Fig. I). It will be seen that the quartz plate was in reality built up of four pieces, all optically finished with extreme accuracy. Starting with $r, 2$ and 3 were contacted on and heated sufficiently to make these three join up into one piece, but, of course, not too much, or the optical perfection of the surfaces would be spoilt. The protruding edges of 2 and 3 where they meet 4 were then ground and polished so that they extended beyond I a distance equal only to $x 6$ wave-lengths. This distance was measured with the Michelson interferometer, and then 4 was contacted on and the heating process repeated.

In the workshops an accurate screw was being cut similar to that which is used in the Fabry and Perot interferometer. This was done on an automatic electrically controlled lathe. Whenever the cutting tool reached the end of its stroke, electrical contacts were made, which moved the tool away and brought it back to the beginning of the next cut. The screw, when turned, is rotated from end to end through a long split nut, driven by an electric motor with an automatic reversing gear. The nut contains a thermometer, the temperature of which is read from time to time to avoid over-heating, and this is apparently sufficient for the purpose, though one might have thought that an oil-bath would have kept the temperature more constant. Great care has to be 